\title{
OS LIMITES DA SOBERANIA EM ROUSSEAU
}

\author{
José Veríssimo Teixeira da MATA ${ }^{1}$
}

- RESUMO: Este artigo intenta esclarecer os limites do poder soberano em Rousseau, pela análise dos seguintes conceitos: soberania, vontade geral, cidadania, interesse comum e particular.

- PALAVRAS-CHAVE: Soberania; vontade geral; cidadania; interesse comum; interesse particular.

Pretende-se, neste estudo, fazer uma análise da questão dos limites do poder soberano, nas articulações deste com a vontade geral e a cidadania, a partir do que nos informa o Contrato Social. Cirurgicamente, apontamos, desde já, à guisa de orientação, como referência ponderável, no desenvolvimento deste artigo, os parágrafos, $5^{\circ}, 6^{\circ}$ e $7^{\circ}$ do cap.IV do livro II do Contrato Social. Eis porque nos parece importante situar o lugar desses parágrafos na lógica do texto. Afinal, há no Contrato um encadeamento lógico notável. Há mesmo recurso a um modelo matemático, conforme nos mostra Marcel Françon em seu artigo "Le langage mathématique de Jean-Jacques Rousseau" (1949). Althusser, por sua vez, chama a atenção do leitor para a íntima conexão dos deslocamentos conceituais que estruturariam essa grande obra do gênio filosófico de Rousseau denominada Do Contrato Social.

Pode-se dizer que os nexos das divisões do Contrato Social são muito cerrados em comparação com a lógica normal de outros tratados. Aqui conviria lembrar que o subtítulo do Contrato não é gratuito - Princípios do Direito Político. Nesse subtítulo fica confirmada a herança jurídica, de resto já gravada pelo título Contrato. Afinal, basta ter presente que o contrato é um dos principais institutos do Direito. Nesse quadro, não importa que esse contrato seja, em muitos de seus aspectos, uma construção da ideologia jurídica que mascara a verdadeira essência da obra (Althusser,

1 Ex-Professor do Departamento de Filosofia da Unicamp; ex-Professor do Departamento de Direito Fundamental da Faculdade de Direito da UFG; Assessor de Direito Constitucional da Câmara dos Deputados. 
1967, p.20). Importa, sim, destacar a seqüência lógica que a tradição dos justratadistas confere às suas obras, em que não há passagens vagando no texto. Eis porque é bom retomar, para que sejam marcados alguns aspectos, os títulos dos capítulos do livro II, que precedem o capítulo IV:

Capítulo I - A soberania é inalienável

Capítulo II - A soberania é indivisível

Capítulo III - Se pode errar a vontade civil

Será, pois, correto dizer que esses capítulos dão à soberania e à vontade geral (afinal, aquela não é senão o exercício dessa - Contrato Social - livro II, capítulo II, p.44) uma força avassaladora, com que essa grande idéia reguladora do pensamento político de Rousseau, a vontade geral, parece tudo sorver, numa voracidade que a muitos amedronta. Ainda no livro I, no capítulo intitulado "Do Soberano", assim se pronuncia Jean-Jacques: “... aquele que recusar obedecer à vontade geral a tanto será constrangido por todo um corpo, o que não significa senão que o forçarão a ser livre... (p.36)". Desnecessário lembrar o peso dessa afirmação, ainda que seja sempre útil avaliar o campo em que ela atua. Althusser nos lembra que o projeto rousseauniano tem duas preliminares: uma determinada forma de anulação prática das diferenças econômicas e a formação de uma opinião ativa (cidadania) favorável à vontade geral, representada pela própria opinião, pelas leis, pela educação e pela religião civil. Essas preliminares se encarregariam de pôr fim ou reduzir a um minimum minimorum os interesses particulares referentes a grupos, partidos, associações e classes sociais que dificultariam a emergência efetiva da vontade geral. Evidentemente que, para a soberania ou a vontade geral se imporem, em um mundo permeado pela segmentação e pela divisão e contradição dos interesses, elas teriam que entrar em choque a todo o tempo contra todos ou quase todos. Questão mais interessante talvez seja, supondo as condições ideais da sociedade de Rousseau satisfeitas, perguntar qual é o campo de atuação da vontade geral, isto é, o espaço em que ela interviria forçando o indivíduo renitente a ser livre. Trata-se, em outras palavras, de determinar os limites do poder soberano. Ora, Rousseau deu ao capítulo IV do livro II do Contrato Social o seguinte título: "Dos Limites do Poder Soberano". Esse dado não nos pode escapar, pois já denuncia o esforço formidável de colocar e resolver um dos problemas fundamentais da Filosofia Política e, especialmente, da Filosofia de Rousseau embutida no Contrato Social - Limitar o Poder Absoluto da Soberania, isto é, limitar o campo de atuação da vontade geral. Trata-se, sem dúvida, de empresa das mais difíceis.

\section{Dos limites do Poder Absoluto}

Já no primeiro parágrafo do capítulo IV, do livro II, lê-se: "Assim como a natureza dá a cada homem poder absoluto sobre todos os seus membros, o pacto social dá ao 
corpo político um poder absoluto sobre todos os seus, e é esse mesmo poder que, dirigido pela vontade geral, ganha, como já disse, o nome de soberania".

Uma primeira limitação do campo da soberania vem logo no parágrafo seguinte: "Mas além da pessoa pública, temos de considerar as pessoas particulares que a compõem, e cuja vida e liberdade naturalmente independem dela. Trata-se, pois, de distinguir os direitos respectivos dos cidadãos e do soberano, e os deveres que os primeiros devem desempenhar na qualidade de súditos, do direito natural de que devem gozar, na qualidade de homens". Ora, esse parágrafo sugere um campo em que a soberania não intervém - o campo do direito natural, de que devemos gozar como homens. Esse campo seria representado, segundo Salinas (1987, p.33), "pelas liberdades sagradas, a liberdade de ir-e-vir, a liberdade de opinião, a liberdade do pensamento etc...., que protegem o indivíduo do arbítrio". Sucede que esse campo é, ele próprio, conseqüência de uma intervenção originária do soberano, de sua avaliação sobre o que lhe interessa ou deixa de interessar. O parágrafo $3^{\circ}$ diz: "Relativamente a quanto pelo pacto social, cada um aliena de seu poder, de seus bens e de sua própria liberdade, convém-se em que representa tão só aquela parte de tudo isso cujo uso interessa à comunidade. É preciso convir também em que só o soberano pode julgar dessa importância". Portanto, é à própria vontade geral que cabe dizer o que interessa ou não. Há, de qualquer modo, para o campo dos direitos naturais certa estabilidade, pois a vontade geral só intervém em determinados momentos, sem falar, como notou Salinas, que Rousseau admite como direitos naturais "as liberdades sagradas".

É claro que o cidadão, como súdito do soberano, a este deve prestar os serviços que lhe forem exigidos. Mas o que pode o Soberano exigir do seu súdito? Parágrafo 4\%: "Todos os serviços que um cidadão pode prestar ao Estado, ele os deve desde que os peça o soberano" (p.49). As exigências destes, porém, são limitadas por Rousseau: "este [o soberano], porém, de sua parte, não pode onerar os súditos com qualquer pena inútil à comunidade, nem sequer pode desejá-lo, pois, sob a lei da razão, não menos ou que sob a natureza, nada se faz sem causa...". Noutras palavras, o soberano não pode exigir o que não seja útil à comunidade. Há um princípio teleológico forte que valida as intervenções e é em favor dele que a razão deverá militar. O soberano, mesmo sendo soberano, não pode exigir o que não seja útil à comunidade. Trata-se, com efeito, ainda dentro do quadro dos princípios, de delimitação inequívoca ao espaço da vontade geral. Sempre, pois, que se exigirem sacrifícios inúteis à comunidade, o cidadão poderá identificar usurpação de seus poderes cívicos. Aqui talvez a maior ferramenta do súdito seja o uso da razão, em que Rousseau, a essa altura do texto, deposita inteira confiança. Mas, forçoso é reconhecê-lo, enquanto exige que se observem os valores da comunidade, que se respeitem as leis ou que se observe 0 campo do direito natural, Rousseau não escapa do quadro clássico de uma jusfilosofia, que tem seus contornos desenhados pela lilberdade como negatividade, a partir da não-interferência nas esferas individuais. Veremos, porém, já nos parágrafos seguintes, como o grande Jean-Jacques rompe com esse quadro, afirmando, de modo 
singular, o seu gênio e aquilo que Goldschmidt (1984, p.159) denominou de "impulsão revolucionária" do Contrato Social.

\section{A especificidade dos limites da soberania em Rousseau}

"Os compromissos que nos ligam ao corpo social só são obrigatórios por serem mútuos, e tal é a sua natureza, que, ao cumpri-los, não se pode trabalhar por outrem sem também trabalhar para si mesmo. Por que é sempre certa a vontade geral e por que desejam todos constantemente a felicidade de cada um, senão por não haver ninguém que não se aproprie da expressão cada um e não pense em si mesmo ao votar por todos? - eis a prova de que a igualdade de direito e a noção de justiça, por aquela determinada, derivam da preferência que cada um tem por si mesmo, e, conseqüentemente, da natureza do homem; a prova de que a vontade geral, para ser verdadeiramente geral, deve sê-lo tanto no objeto quanto na essência; a prova de que essa vontade deve partir de todos para aplicar-se a todos, e de que perde sua explicação natural quando tende a algum objetivo individual e determinado, porque então, julgando aquilo que nos é estranho, não temos qualquer princípio de eqüidade para guiar-nos" (Rousseau, 1973, p.49). Esse parágrafo revela um dos giros singulares do pensamento rousseauniano. Aqui Jean-Jacques admite, a exemplo de Hobbes e Locke, os interesses egoístas de cada um. Não se trata de construir uma sociedade em cima do desinteresse: “...as necessidades egoístas e extremamente urgentes de cada indivíduo. São estas necessidades que motivam imediatamente a preocupação da liberdade..." (Strauss, 1984, p.88). A singularidade de Rousseau está, primeiramente, no fato de distinguir o interesse do indivíduo, o verdadeiro interesse, dos outros interesses particulares (classes, grupos, corporações) e submeter os interesses do indivíduo à vontade geral; segundo, em perceber que esses interesses do indivíduo não trabalham contra a vontade geral, mas, de modo contrário, são eles próprios que a fundam. Mas aqui, como já sublinhara o lúcido Althusser, é necessário isolar 0 interesse do indivíduo dos outros que artificialmente se lhe juntam em função da inserção do homem em grupos que não expressariam a vontade geral. $O$ interesse do indivíduo, desnudado de sua cobertura adquirida na inserção em grupamentos particulares, revelaria, da mesma maneira que um objeto lógico privilegiado particular revela o universal, o interesse comum. Essa diferenciação radical entre a natureza dos interesses pode ser mais bem visualizada como traço inequívoco da singularidade de Rousseau quando é colocada diante do pensamento de seus predecessores, como 0 Barão de Pufendorff, que diz (Du citoyen - livro II, capítulo V, p.53): "A maior parte das ações de um cidadão deve também reportar-se ao bem do Estado, que parece freqüentemente não estar de acordo com o dos particulares". Ora, o mérito de Rousseau é, precisamente, vislumbrar na própria esfera dos interesses particulares 
um corte profundo entre o interesse do indivíduo e os outros interesses particulares. Esse fato é que faz compreensível o esforço da vontade geral em forçar o indivíduo a ser livre, isto é, em tomar medidas para que o indivíduo se afaste dos interesses particulares que não sejam propriamente interesses individuais. Na base desse projeto político está toda a antropologia de Rousseau, seu esforço em descobrir o homem e em desnudá-lo. Esse projeto político permite a Rousseau uma enorme liberdade crítica, que lhe dá oportunidade de desferir poderosos golpes em tudo e em quase todos que, de alguma forma, privatizem os interesses. Talvez seja esse elemento uma das causas da viva atualidade do problema rousseauniano, pois mesmo antes da derrocada do Antigo Regime, ele já denuncia claramente a insuficiência do projeto nascente. Como diz Leo Strauss, para Rousseau, "O homem é livre, no sentido político, se está sujeito somente à vontade impessoal da sociedade, e não à vontade particular ou privada do indivíduo" (1984, p.89). Noutras palavras, o cidadão, uma das noções mais ativas no interior do pensamento de Rousseau, deve, ao velar pela cidadania e pela expressão da vontade geral, que ele próprio constitui com os outros cidadãos, supor uma figura com todas as determinações que o indivíduo eventualmente carregue (patrão, operário, senhor, escravo etc.) e dela se afastar à medida que essas determinações o distanciam daquilo que Althusser (1967, p.36) chamou de "intérêt particulier pur". Portanto, contra aqueles que opõem o interesse individual à possibilidade de fundação de uma sociedade em que nenhum indivíduo se submete a outro, Rousseau levanta a tese de que é o próprio interesse do indivíduo que aponta para a "cidade dos fins". Comentando o papel do interesse em Rousseau, Althusser assim se expressa: "C'est un des points de la théorie de Rousseau qui rend décidément impossible toute 'lecture' kantienne en terme de moralité." ... "Para Rousseau, o interesse (que é a forma do amor próprio no sistema das relações sociais, estado de guerra ou sociedade de contrato) jamais pode ser 'posto entre parênteses', 'ou transcendido', senão por ele próprio" (p.29).

De que modo o parágrafo $5^{2}$, do capítulo II, do livro IV é importante na limitação do Poder Soberano? De várias formas. Primeiramente, ele indica com muita precisão que o espaço da vontade geral não coincide com o espaço da "privatização" dos interesses do indivíduo. Seria, com efeito, possível ao cidadão, supondo as condições ideais da cidadania, identificar as aparições pontuais de focos de privatização de interesses e que levam à subordinação do indivíduo às classes, aos grupos ou, simplesmente, a outros indivíduos. A leitura do parágrafo V supõe, de alguma maneira, o "homem nu" rousseauniano, não no sentido de sua aparição pré-contratual, nem no sentido de que o "cada um" diga respeito ao indivíduo carregado de ideologias oriundas de esferas privadas, mas no sentido do "cada um" que se entrega totalmente à vontade geral, mediante a "alienação total" ("Essas cláusulas - referentes ao pacto quando bem compreendidas reduzem-se todas a uma só: a alienação total de cada associado, com todos os seus direitos, à comunidade toda, porque, em primeiro lugar, cada um dando-se completamente, a condição é igual para todos, e, sendo a condição 
igual para todos, ninguém se interessa por torná-la onerosa para os demais" livro I, capítulo VI, p.32). "Mas a alienação total apenas produz, de modo preciso, seus efeitos, porque ela supõe, em si mesma, a eficácia determinante do interesse" (Althusser, 1967, p.29).

Um segundo limite ao Poder Soberano é posto, ainda no parágrafo $5^{\circ}$, do capítulo $\mathrm{IV}$, pela forma da vontade geral: “... a vontade geral, para ser verdadeiramente geral, deve sê-lo tanto no objeto quanto na essência; a prova de que essa vontade deve partir de todos para aplicar-se a todos, e de que perde sua explicação natural quando tende a algum objetivo individual e determinado..." (Rousseau, 1973, p.49). Como diz Leo Strauss (1984, p.88): "Para evitar toda a espécie de dependência pessoal, ou governo privado, cada indivíduo e cada coisa devem estar submetidos à vontade social, que apenas pode exprimir-se sob a forma de leis gerais, para cujo estabelecimento cada um deve ter podido contribuir com seu voto". Em verdade, ao fixar a natureza necessariamente universal dos objetivos da vontade geral, o parágrafo $5^{0}$ articula-se ao 6", sendo esse meramente explicativo da tese já posta no anterior: "Com efeito, desde que se trata de fato de um direito particular sobre algo que não esteja regulamentado por convenção geral e anterior, a questão se torna contenciosa: é um processo em que os particulares interessados representam uma das partes e o público a outra, mas no qual não vejo nem que lei observar, nem que juiz pronunciar-se". Pode-se dizer que Rousseau apresenta aqui nesses dois últimos parágrafos um dos limites mais fortes à vontade geral e ao poder soberano - a estrutura de seu objeto. A vontade geral não pode, como vontade geral, pronunciar-se sobre fato concreto, determinado ou particular. Os fatos determinados e particulares pertencem a uma esfera à qual a vontade geral não penetra nem toca. Mesmo que um corpo de cidadãos quisesse, ele não teria o poder de exercer a sua soberania sobre fatos particulares, pois Soberania e vontade geral de um lado e fatos particulares, de outro, constituem duas esferas sem qualquer intersecção.

O que vem de ser exposto não nos deve levar a crer que o cidadão não tenha que se decidir sobre assuntos não-gerais, mas devemos considerar simplesmente que, ao fazê-lo, não exerce a soberania. Exerce, porém, funções estatais (magistraturas judiciais, administrativas) postas no quadro geral da sociedade pelas linhas traçadas pelo soberano - "Ouando, por exemplo, o povo de Atenas nomeava ou destituía a seus chefes, concedia honrarias a um, impunha penas a outros, por múltiplos decretos especiais, indistintamente exercia todos os atos do governo, o povo não tinha mais vontade geral propriamente dita, não agia mais como soberano, mas como magistrado". O campo de atuação da vontade geral é determinado formalmente por funções de natureza geral, que dizem respeito a todos os membros da sociedade. O poder soberano tem, pois, essa limitação formal bem nítida. Nesse quadro, o corpo político pode até se comportar de maneira una diante de assunto privado determinado, que não seja dotado de inequívoca universalidade. Entretanto, para Rousseau, essa manifestação não traz a marca da vontade geral. O parágrafo $7^{\circ}$ é, a esse respeito, 
esclarecedor: "On doit concevoir par là que ce qui généralise la volonté est moins le nombre de voix que l'intérêt commun qui les unit; car dans cette instituition, chacun se soumet nécessariemente aux conditions qu'il impose aux autres: accord admirable de l'intérêt et de la justice, qui donne aux déliberations communes un caractère d'équité qu'on voit évanouir dans la discusion de toute affaire particulière, faute d'interét commun qui unisse et identifie la règle du juge avec celle de la partie".

\section{Interesse comum e interesse individual}

Convém esclarecer a relação entre o interesse individual e o interesse comum. Devemos entender por interesse individual o interesse particular puro, como foi dito neste texto anteriormente. Ora, parece que para a compreensão dos significados desses conceitos importam também as referências aos objetos, para os quais eles apontam, sejam estes particulares ou universais. Embora Rousseau não o explicite, deve-se compreender que ele nos coloca aqui diante do mesmo problema abordado ante a vontade geral. De resto, trata-se de noções conexas. O interesse é o que faz mover a vontade.

Considerando o interesse individual, numa sociedade ideal, isto é, que supere a fragmentação dos corpos-não-universais, têm-se ainda assim dois campos nos quais o interesse particular puro se manifestaria, dependendo da estrutura do objeto que lhe sirva de conteúdo - ou o particular ou o universal. Quando o interesse do indivíduo (o particular puro) se volta para os objetos universais da sociedade, ele se apresenta em sua face "comum" - é, nesse caso, interesse comum. Nessa hipótese, poder-se-ia considerar, sem risco de afirmar algum paralogismo, que "o interesse do indivíduo é o interesse comum". Entretanto, quando o interesse do indivíduo se refere a objetos não-universais, será vã qualquer tentativa de identificá-lo ao interesse comum. Tudo se passa como se o interesse particular puro tivesse duas faces - uma que se volta aos objetos determinados e outra aos universais. Nada impediria a possibilidade de a unanimidade se realizar sobre um objeto determinado. Nesse caso, entretanto, mais do que em qualquer outro, deve-se ter presente o que dissera Rousseau: "On doit concevoir par là que ce qui généralise la volonté est moins le nombre de voix que l'intérêt commun qui les unit...". ${ }^{2}$ Ora, é esse interesse comum, que funda um egoísmo original, que permite a constituição da vontade geral, ou como diz Jean-Jacques, "que generaliza a vontade".

\footnotetext{
2 Foram mantidas as passagens em francês, pois há na sua tradução por Lourdes Santos Machado uma inversão de sentido: "... menos do que o número de votos, aquilo que generaliza a vontade é o interesse comum que os une..." (p.50).
} 


\section{O cidadão e a vontade geral}

Há uma diferença sensível entre Rousseau e outros pensadores que colocam o problema dos limites da soberania. Normalmente, divide-se em esferas distintas a competência do Estado e dos súditos, indicando o que cabe aos cidadãos. Ao súdito cabe se submeter às condições que lhe são impostas, quando muito pode exercitar a liberdade num espaço preliminarmente definido e que de nenhum modo toca as grandes funções do Estado. No caso das teorias do liberalismo, aparece um espaço em que o indivíduo pode mover-se sem interferir na liberdade do outro, e sem interferência do outro em suas atividades privadas. Ora, o toque original de Rousseau pode ser visualizado em toda a sua pujança, diante desse problema, no fato de o autor do Contrato Social não dissociar o exercício da liberdade individual do exercício da plasmação das grandes definições políticas. Nesses ponto, Rousseau é ainda mais radical do que conseguimos ser ainda hoje, pois, no máximo, tendemos a ver como liberdade a possibilidade de participar da plasmação das grandes definições políticas, agregada à esfera de nossa liberdade individual. Quando essa possibilidade nos é dada, exercitamo-la ou não. Identificamos essa escolha com a própria liberdade. Para Rousseau, o quadro é qualitativamente diferente. No campo da plasmação das convenções gerais, o indivíduo deve exercer a sua cidadania. Ele deve ajudar a dar a si mesmo a lei, para retomarmos a transcrição kantiana da proposta política de Rousseau para o plano da moral. O indivíduo não pode subtrair-se de participar da plasmação das convenções gerais. $E$ isso deve afigurar-se-lhe natural, uma vez que a sua essência política é atributo a que ele não pode renunciar: "... pois nessa instituição cada um se submete necessariamente às condições que impõe aos outros ..." "Noutras palavras, as condições que cada um impõe aos outros são as mesmas que impõe a si mesmo. O corpo de cidadãos dá a si mesmo as leis, e assim é livre."

A liberdade é, desse modo, não apenas o espaço que a lei reservou para que desenvolvamos as nossas esferas privadas, mas é também o fato de nos darmos a nós mesmos a lei. Que o momento do corpo de cidadãos intervir seja disciplinado pela engenharia política (Legislador) é coisa que muito preocupou a Rousseau e que escapa dos objetivos deste trabalho. Entrentanto, será sempre bom dizê-lo, sem essa intervenção cidadã, o Estado-modelo de Rousseau não funciona. Inspirado, como é sabido, na democracia ateniense, na imagem da Pólis, e preocupado em garantir as "liberdades sagradas" que já despontavam. Rousseau termina fundando teoricamente um novo espaço de liberdade, que transcende e supera as experiências históricas que o animaram. Essa "impulsão revolucionária" do Contrato Social, para retomarmos Goldschmidt, parece para sempre destinada a conservar o seu vigor e a sua virilidade. Esse fato explicaria porque o "ingênuo" Rousseau de muitos é cada vez mais sério e atual, ao figurar obrigatoriamente em qualquer leitura mais profunda do Estado e da Cidadania. 
A pergunta, porém, que se poderia colocar, a esse momento, é a seguinte: em que medida a cidadania determina o campo de atuação da vontade geral? Ora, a vontade geral é precisamente o que diz a cidadania, na hora certa e em relação a objetivo geral. Não existe, pois, para se falar em termos de "campo de atuação", vontade geral nem soberania aquém e além da cidadania. Essa, arrisco a dizê-lo, é sem dúvida, a lição mais radical e mais rousseauniana do Contrato Social.

\section{Conclusão}

A questão dos limites do poder soberano é, sem dúvida, das mais difíceis com que se deparam os teóricos do Estado. Rousseau deu um contributo original para que se pensem os limites do poder soberano. Fez isso desenvolvendo a noção de vontade geral e precisando o seu principal constituinte (a cidadania), bem como dando teoricamente a estrutura de seu objeto - objetos sociais gerais. Valeu-se da noção de interesse, de modo original, fundando nela o movimento da cidadania. Ademais, integrou esta ao espaço da liberdade individual, não a separando da esfera comum (política).

De fato, o problema do poder soberano, de seus contornos e limites, em sua relação com a vontade geral e a cidadania, é dos veios mais férteis a serem explorados na necessária releitura do Contrato Social. Convite que esta obra faz sempre pela simples razão de que se trata de clássico que transpôs definitivamente o tempo.

MATA, J. V. T. da. The limits of sovereignty in Rousseau. Trans/Form/Ação (São Paulo), v.18, p.95-104, 1995.

- ABSTRACT: This article intends to make clear the boundaries of the sovereign power in Rousseau, by the analysis of the following concepts: sovereignty, general will, citizenship, common interest, private interest.

- KEYWORDS: Sovereignty; general will; citizenship; common interest; private interest.

\section{Referências bibliográficas}

1 ALTHUSSER, L. Sur le contrat social. Cahiers pour l'analyse, n.6, 1967.

2 FRANÇON, M. Le langage mathématique de Jean-Jacques Rousseau. ISIS: An International Review Devoted to the History of science and its cultural influences, v.40, p.341-4, 1949. 
3 GOLDSCHMIDT, V. Individu et communauté. In: Pensée de Rousseau. Éditions du Seuil, 1984.

4 PUFENDORFF, B. de. Le droit de la nature et des gens, ou Système Général des Principes les plus importants de la morale, de la jurisprudence et de la politique. Trad. Barbeyrac. Caen: Université de Caen, 1987. (Bibliothèque de Philosophie Politique et Juridique).

5 ROUSSEAU, J. J. Do contrato social. In: Do contrato social; Ensaio sobre a origem das línguas; Discurso sobre a origem e os fundamentos da desigualdade entre os homens; Discurso sobre as ciências e as artes. São Paulo: Abril Cultural, 1973. (Coleção Os Pensadores)

6 Contrat social. Paris: Librairie Garnier Frères, s.d.

7 SALINAS, L. R. Democracia, liberdade e igualdade. In: A constituinte em debate. São Paulo: Sofia Editora, SEAF, 1987.

8 STRAUSS, L. L'intention de Rousseau. In: Pensée de Rousseau. Paris: Éditions du Seuil, 1984. 